\title{
Relationship between oxysterols and mild cognitive impairment in the elderly: a case-control study
}

\author{
Quanri Liu, Yu An, Huanling Yu, Yanhui Lu, Lingli Feng, Chao Wang and Rong Xiao*
}

\begin{abstract}
Background: To investigate the relationship between oxysterols and mild cognitive impairment (MCl) in a matched case-control study.

Methods: The plasma levels of four oxysterols, 27-hydroxycholesterol (27-OHC), 24S-hydroxycholesterol (24S-OHC), $7 a-h y d r o x y c h o l e s t e r o l(7 a-O H C)$ and $7 \beta-$ hydroxycholesterol $(7 \beta-O H C)$, were analyzed by High Performance Liquid Chromatography-Mass Spectrometry (HPLC-MS) and compared between $70 \mathrm{MCl}$ patients and 140 matched controls with normal cognition. The odds ratio (OR) was calculated using logistic analyses to assess the association between oxysterols and $\mathrm{MCl}$.
\end{abstract}

Results: Compared with controls with normal cognition, plasma level of 27-OHC was significantly higher in $\mathrm{MCl}$ patients. Logistic analyses suggested high plasma level of 27-OHC was significantly associated with $\mathrm{MCl}$ even after multivariate adjustment ( $\mathrm{OR}=2.86,95 \% \mathrm{Cl}: 1.52 \sim 5.37)$.

Conclusions: Our findings suggested that the increased plasma level of $27-\mathrm{OHC}$ was associated with $\mathrm{MCl}$, suggesting high plasma levels of 27-OHC may pay an important role in the development of $\mathrm{MCl}$.

Keywords: Oxysterols, 27-hydroxycholesterol, Alzheimer's disease, Mild cognitive impairment, MoCA, Aß1-40, Aß1-42

\section{Background}

Alzheimer's disease (AD) is the most commonly recognized cause of dementia by memory loss and other intellectual symptoms serious enough to affect daily life in the elderly [1]. It contributes to premature death of elders after being diagnosed for 3 to 9 years [2]. MCI is the preclinical stage of $\mathrm{AD}$ with gradual cognitive decline but no influence on daily life activities. It is accepted that early intervention in $\mathrm{MCI}$ including decreasing the risk factors is useful and therefore many studies have focused on this stage [3].

Substantial epidemiological and molecular evidence has indicated that hypercholesterolemia is an important risk factor for neurodegenerative diseases [4]. However, clinical studies by using statins to lower the cholesterol for preventive and therapeutic management of neurodegeneration

\footnotetext{
* Correspondence: xiaor22@ccmu.edu.cn

School of Public Health, Beijing Key Laboratory of Environmental Toxicology,

Capital Medical University, No.10 Xitoutiao, You An Men Wai, Beijing 100069, Fengtai District, China
}

did not show the effects [5]. In addition, cholesterol in the blood cannot pass the blood brain barrier into central nervous system (CNS) [6]. The above facts cannot support the role of high plasma level of cholesterol in $\mathrm{AD}$ or $\mathrm{MCI}$.

Oxysterols including $27-\mathrm{OHC}, 24 \mathrm{~S}-\mathrm{OHC}, 7 \alpha-\mathrm{OHC}$ and $7 \beta-\mathrm{OHC}$ are the oxidized derivatives of cholesterol, which can not only pass the blood brain barrier [7] but also have cytotoxic and pro-apoptotic properties $[8,9]$. $27-\mathrm{OHC}$ is the most abundant circulating oxysterol mainly produced in the liver [10]. Previous studies have also demonstrated an influx of the $27-\mathrm{OHC}$ from the circulation into the brain [11]. Despite the fact that cholesterol cannot pass the blood-brain barrier, hypercholesterolemia Since there is a close correlation between circulating cholHeverin et al. [16] has demonstrated that treatment of mice with dietary cholesterol causes significant memory 
impairment and 27-OHC mediates the negative effects of dietary cholesterol on cognition. Therefore, there is possibility that $27-\mathrm{OHC}$ is linking the excessive diet cholesterol or hypercholesterolemia and neurodegenerative conditions. A recent study showed a significant accumulation of 27-OHC in the brain of patients with $\mathrm{AD}$ [17]. In addition, one animal study showed the level of 27-OHC in 12-month-old rats is higher than that in 8-month-old rats, suggesting the accumulation of $27-\mathrm{OHC}$ in the brain with age [18].

Despite the accumulated evidence about the relationship of oxysterols with neurodegenerative diseases such as $\mathrm{AD}$, there are no direct data from humans to evaluate the relationship between oxysterols and MCI. The aim of this study was to evaluate plasma levels of $27-\mathrm{OHC}$, $24 \mathrm{~S}-\mathrm{OHC}, 7 \alpha-\mathrm{OHC}$ and $7 \beta-\mathrm{OHC}$ in the elderly with and without MCI and attempt to establish potential relationships between these oxysterols and cognitive function.

\section{Methods}

\section{Subjects and cognitive assessment}

Seventy hospitalized subjects diagnosed as MCI and 140 controls with normal cognition were recruited from Xuan Wu Hospital in Beijing, China. The study design was ethically approved by the Ethics Committee of Capital Medical University (2013SY35). The process was explained for all subjects before the written informed consent was obtained. Controls were age- ( \pm 5 years), sex- and education- matched with MCI patients. The subjects with the history of a cerebrovascular event, malignant tumor and psychiatric illness or other neurological disease and statin or hypnotic sedative drugs abuse were excluded from the study. Cognitive function was evaluated by professional interviewers using the Mini-Mental State Examination (MMSE) [19] and Montreal Cognitive Assessment (MoCA) [20]. MMSE is commonly used to screen for dementia but insensitive to MCI while the MoCA was specially developed for detection of MCI [20]. All MCI patients should primarily satisfy the criteria of $\mathrm{MCI}$ including the following: (1) normal general cognitive function and absence of dementia that is sufficient to satisfy MMSE score of $>19$ for illiterate individuals, $>22$ for individuals with 1 to 6 years of education and $>26$ for individuals with 7 or more years of education; (2) mild impairment of cognitive functioning evaluated by MoCA score of $\leq 14$ for illiterate individuals, $\leq 19$ for individuals with 1 to 6 years of education and $\leq 24$ for individuals with 7 or more years of education. If the subjects meet the above $\mathrm{MCI}$ criteria, they will visit a neurologist to make the final diagnosis.

\section{Demographic, clinical and anthropometric assessment} Demographics (age, gender, education, weight and height), lifestyle habits (current smoking status and drinking status), history of hypertension, coronary heart disease, diabetes and cerebrovascular disease were collected by self-reported questionnaire. Body mass index (BMI) was calculated as weight $(\mathrm{kg}) /$ height ${ }^{2}\left(\mathrm{~m}^{2}\right)$. Current smoking status and drinking status were binary variables. Subjects were classified as smokers if they reported smoking three or more cigarettes a week for more than six months before enrollment and non-smokers if their cigarettes consumption was lower than this. Drinkers were identified by reporting alcohol consumption three or more times a week for more than six months before enrollment and non-drinkers lower than this.

\section{Laboratory measurements}

The $0.6 \mathrm{~mL}$ tubes containing EDTA anticoagulant were used to collect fasting venous blood samples. The plasma samples were harvested after centrifugation at $3000 \mathrm{rpm}$ for $10 \mathrm{~min}$ at $4{ }^{\circ} \mathrm{C}$ and stored frozen at $-80{ }^{\circ} \mathrm{C}$ until measurement. The levels of plasma triglycerides (TG), total cholesterol (TC), high-density lipoprotein cholesterol (HDL-C), low-density lipoprotein cholesterol $(\mathrm{LDL}-\mathrm{C})$ and fasting blood glucose (FBG) were measured on a HITACHI 7600 analyzer. $A \beta 1-40$ and $A \beta 1-$ 42 plasma levels were evaluated by ELISA kit.

Plasma levels of oxysterols were measured using High Performance Liquid Chromatography-Mass Spectrometry (HPLC-MS) as described by Ines Burkard, et al. [21] with slight modifications. Briefly, $0.1 \mathrm{~mL}$ of plasma sample was transferred to a screw-capped vial and $100 \mathrm{ng}$ of 19-hydroxycholesterol (19-OHC) was also added to the vial serving as internal standard. Alkaline hydrolysis was performed at $50{ }^{\circ} \mathrm{C}$ water bath for $2 \mathrm{~h}$ after adding $1.5 \mathrm{~mL}$ of $1 \mathrm{M}$ ethanolic sodium hydroxide. Phosphoric acid (50\%) and $1 \mathrm{~mL}$ of phosphate buffer were added to the samples to adjust $\mathrm{pH}$ to 7 . Supernatant was harvested after the centrifugation at $1000 \mathrm{~g}$ for $5 \mathrm{~min}$ and then applied to the C18 cartridges for solid-phase extraction. The eluted substances were dried at $30{ }^{\circ} \mathrm{C}$ and dissolved in $100 \mathrm{~mL}$ of methanol for future test. HPLC with an Angilent G1312B HPLC Pump and an Angilent C18 column $(0.35 \mu \mathrm{m}$ bead size; $4.6 \times$ $250 \mathrm{~mm}$ ) were used for the measurement of oxysterols. Quantification of oxysterols was performed using the multiple reaction monitoring (MRM) mode.

\section{Statistical analysis}

The data were expressed by means \pm standard deviations for normally distributed continuous variables, medians (interquartile ranges) for non-normally distributed continuous variables and frequencies (percentages) for categorical variables. Independent t-test and Mann Whitney $U$ test were used for continuous variables and Chi-square test for categorical variables to compare differences between $\mathrm{MCI}$ and control groups. 27-OHC, 
$24 \mathrm{~S}-\mathrm{OHC}, 7 \alpha-\mathrm{OHC}$ and $7 \beta-\mathrm{OHC}$ levels were classified into high and low levels by their medians. Univariate conditional logistic regression was used to evaluate the association between four oxysterols (treated as categorical variables) and MCI risk. Multivariate analysis was used to adjust demographic, clinical and anthropometric characteristics. Spearman rank correlation test was calculated to assess correlation coefficients. And $P<0.05$ was considered statistically significant. All of the statistical analyses were performed using SPSS (version 18.0).

\section{Results}

This study included $70 \mathrm{MCI}$ patients (35 men and 35 women) and 140 controls with normal cognitive state (70 men and 70 women). Demographic and clinical characteristics of all the subjects were summarized in Table 1. Drinkers $(P=0.03)$, MoCA scores $(P<0.01)$, A $\beta 1-40(P<0.01)$ and A $\beta 1-42(P<0.01)$ were observed with significant differences between $\mathrm{MCI}$ and control group.

The plasma levels of four oxysterols were present in Table 2. There was significant difference between the two groups regarding the plasma $27-\mathrm{OHC}$ levels but no significant differences in $24 \mathrm{~S}-\mathrm{OHC}, 7 \alpha-\mathrm{OHC}$ and $7 \beta-\mathrm{OHC}$ levels.

Table 3 using univariate analysis showed that only high plasma level of 27-OHC was associated with MCI $(\mathrm{OR}=3.21,95 \% \mathrm{CI}: 1.76 \sim 5.85)$. Four oxysterols were classified into high and low levels by their medians.

Table 4 showed the significant association between high plasma level of 27-OHC and MCI persisted even after adjustment (OR = 2.86, $95 \%$ CI: $1.52 \sim 5.37)$.

Spearman correlation analyses showed that the plasma level of 27-OHC was positively correlated with that of $A \beta 1-40$ and $A \beta 1-42$ and negatively correlated with $\mathrm{MoCA}$ scores (Fig. 1a-c).

Table 1 Demographic and clinical characteristics of $\mathrm{MCl}$ patients and controls

\begin{tabular}{|c|c|c|c|c|c|}
\hline & \multirow{2}{*}{$\begin{array}{l}\mathrm{MCl} \\
(n=70)\end{array}$} & & \multirow{2}{*}{$\begin{array}{l}\text { Controls } \\
(n=140)\end{array}$} & & \multirow[t]{2}{*}{$P$ value } \\
\hline & & & & & \\
\hline \multicolumn{6}{|l|}{ Demographic and risk factors } \\
\hline Age (y) & 59 & $(61-72)$ & 60 & $(62-69)$ & - \\
\hline Male, \% & 50.0 & & 50.0 & & - \\
\hline Education (y) & & & & & - \\
\hline$\leq 9,(\%)$ & 44.3 & & 44.3 & & \\
\hline $9 \sim 12,(\%)$ & 25.7 & & 25.7 & & \\
\hline$\geq 12,(\%)$ & 30.0 & & 30.0 & & \\
\hline Smokers, \% & 32.9 & & 22.9 & & $0.12^{\mathrm{a}}$ \\
\hline Drinkers, \% & 22.9 & & 37.9 & & $0.03^{\mathrm{a}}$ \\
\hline Hypertension, \% & 41.4 & & 41.4 & & $1.00^{\mathrm{a}}$ \\
\hline Coronary Heart Disease, \% & 7.1 & & 8.6 & & $0.72^{\mathrm{a}}$ \\
\hline Diabetes, $\%$ & 20.0 & & 12.1 & & $0.13^{\mathrm{a}}$ \\
\hline Cerebrovascular Disease, \% & 2.9 & & 2.9 & & $1.00^{\mathrm{a}}$ \\
\hline $\mathrm{BMI}\left(\mathrm{kg} / \mathrm{m}^{2}\right)$ & 24.42 & \pm 2.53 & 25.25 & \pm 3.78 & $0.10^{\mathrm{b}}$ \\
\hline \multicolumn{6}{|l|}{$\mathrm{MCl}$ screening } \\
\hline MMSE scores & 28 & $(27-29)$ & 28 & $(27-30)$ & $0.07^{c}$ \\
\hline MoCA scores & 22 & $(19-23)$ & 26 & $(25-28)$ & $<0.01^{\mathrm{c}}$ \\
\hline \multicolumn{6}{|l|}{ Laboratory } \\
\hline FBG $(\mathrm{mmol} / \mathrm{L})$ & 5.58 & $(5.20-6.25)$ & 5.54 & $(5.09-6.14)$ & $0.38^{c}$ \\
\hline $\mathrm{TG}(\mathrm{mmol} / \mathrm{L})$ & 1.38 & $(0.97-2.03)$ & 1.41 & $(1.01-2.07)$ & $0.69^{c}$ \\
\hline $\mathrm{HDL}-\mathrm{C}(\mathrm{mmol} / \mathrm{L})$ & 1.4 & $(1.18-1.60)$ & 1.4 & $(1.10-1.53)$ & $0.71^{c}$ \\
\hline LDL-C (mmol/L) & 2.57 & \pm 0.75 & 2.76 & \pm 0.74 & $0.09^{b}$ \\
\hline $\mathrm{TC}(\mathrm{mmol} / \mathrm{L})$ & 4.56 & \pm 1.00 & 4.73 & \pm 0.85 & $0.20^{\mathrm{b}}$ \\
\hline $\mathrm{A} \beta 1-40(\mathrm{pg} / \mathrm{mL})$ & 992.08 & \pm 208.92 & 589.08 & \pm 214.39 & $<0.01^{\mathrm{b}}$ \\
\hline $\mathrm{A} \beta 1-42(\mathrm{pg} / \mathrm{mL})$ & 795.01 & \pm 177.43 & 451.54 & \pm 209.08 & $<0.01^{b}$ \\
\hline
\end{tabular}

${ }^{a}$ Data presented as frequencies (percentages) were compared between 2 groups by using Chi-square test

${ }^{\mathrm{b}}$ Data presented as means \pm standard deviations were compared between 2 groups by using the Student t-test

${ }^{c}$ Data presented as medians (interquartile ranges) were compared between 2 groups by using the Mann Whitney $U$ test 
Table 2 Plasma levels of four oxysterols in MCl patients and controls ( $\mathrm{ng} / \mathrm{mL}$ )

\begin{tabular}{lllll}
\hline Oxysterol & $27-\mathrm{OHC}$ & $245-\mathrm{OHC}$ & $7 \mathrm{a}-\mathrm{OHC}$ & $73-\mathrm{OHC}$ \\
\hline $\mathrm{MCl}$ & $74.23(55.34-99.50)$ & $44.55(28.91-60.04)$ & $47.48(31.89-65.47)$ & $51.20(38.84-72.13)$ \\
$(n=70)$ & & $44.69(35.81-65.60)$ & $45.57(31.10-63.78)$ & $52.07(37.47-75.86)$ \\
$\begin{array}{l}\text { Controls } \\
(n=140)\end{array}$ & $56.48(43.71-82.13)$ & & $0.68^{a}$ & $0.87^{\mathrm{a}}$ \\
$P$ value & & $0.69^{\mathrm{a}}$ & \\
\hline
\end{tabular}

${ }^{a}$ Data presented as medians (interquartile ranges) were compared between 2 groups by using the Mann Whitney $U$ test

\section{Discussion}

In these four oxysterols, 27-OHC is the major cholesterol metabolite in the circulation and mainly produced from cholesterol in periphery and synthesized in almost all cells by the cytochrome P-450 enzyme CYP27A1 located in the inner mitochondrial membranes. A significant association between high plasma level of 27-OHC and MCI was observed in this study. Our results were in accordance with the previous studies that described 27$\mathrm{OHC}$ level in blood was negatively associated with cognitive performance in aging population and was significantly higher in $\mathrm{AD}$ patients [22, 23]. However, subjects with neurological diseases, such as $\mathrm{AD}$ or other types of dementia, were ruled out by exclusion criteria in our study for more reliable results prior to medication. There was also a negative correlation between plasma $27-\mathrm{OHC}$ level and MoCA scores $(\mathrm{r}=-0.269, P=0.001)$. The negative correlation indicates that $27-\mathrm{OHC}$ production in the blood is expected to increase with severity of cognitive impairment.

Previous research has indicated that subjects with high A $\beta$ levels showed increased cognitive impairment [24]. Marwarhaet al [25] has found that 27-OHC induced 3fold increase in $A \beta 1-42$ and 1.5-fold increase in A $11-40$ levels in the organotypic slices from rabbits. Moreover, Prasanthiet al [26] treated human neuroblastoma SHSY5Y cells with $27-\mathrm{OHC}$ and found a substantial increase in A $\beta 1-42$ levels compared to untreated cells. Our study has also shown MCI patients had higher plasma $A \beta 1-40$ and $A \beta 1-42$ levels than controls with normal cognition $(P<0.01)$. Simultaneously, a good positive correlation between plasma levels of $A \beta 1-42$ and

Table 3 Odds ratio of $\mathrm{MCl}$ for oxysterols in univariate regression analysis

\begin{tabular}{llll}
\hline Oxysterols & \multicolumn{2}{l}{ Odds ratio and $95 \% \mathrm{Cl}$} & \multicolumn{2}{c}{$P$ value } \\
\cline { 2 - 3 } & Low level & High level & \\
\hline $27-\mathrm{OHC}$ & Ref & $3.21(1.76-5.85)$ & $<0.01$ \\
$24 \mathrm{~S}-\mathrm{OHC}$ & Ref & $0.93(0.51-1.68)$ & 0.80 \\
$7 \mathrm{-}-\mathrm{OHC}$ & Ref & $1.26(0.66-2.41)$ & 0.48 \\
$7 \beta-\mathrm{OHC}$ & Ref & $0.89(0.46-1.73)$ & 0.74 \\
\hline
\end{tabular}

The plasma levels of $27-\mathrm{OHC}, 24 \mathrm{~S}-\mathrm{OHC}, 7 \mathrm{a}-\mathrm{OHC}$ and $7 \beta-\mathrm{OHC}$ were classified into high and low levels by their medians
27-OHC $(\mathrm{r}=0.269, P=0.005)$ and a weak but significant correlation of plasma 27-OHC with A $\beta 1-40$ levels ( $r=0.192, P=0.048$ ) were also observed, supporting the hypothesis that 27-OHC may enhance circulating amyloid production and increase the risk of cognitive impairment.

Despite that, studies analyzing the associations between plasma 27-OHC level and cognitive decline yielded conflicting results. Timothy $\mathrm{M}$. Hughes et al. [27] recently found that the increase of plasma 27-OHC levels was related to cerebrovascular disease prior to cognitive decline over many years of follow-up. However, it lacked MRI results for cerebrovascular disease when the volunteers were diagnosed of $\mathrm{AD}$ or $\mathrm{MCI}$ in follow-up. Thus, the question arises whether cerebrovascular disease is the injury factor for cognitive status. In addition, a case-control study has shown that the ratio of 27-OHC to total circulating cholesterol (27$\mathrm{OHC} / \mathrm{Chol}$ ) level is lower in AD and MCI patients than that in controls [28]. There is possibility that oxysterols and cholesterol compete for space within the lipoproteins and they have different scales on space within the lipoprotein, absolute levels of plasma 27-OHC may be higher in MCI compared to controls despite of the decrease of 27-OHC/Chol.

On the other hand, in the brain, cholesterol is removed by conversion to $24 \mathrm{~S}-\mathrm{OHC}$ via CYP46A1 enzyme, which is primarily expressed in neurons. We found no significant difference in $24 \mathrm{~S}-\mathrm{OHC}$ level in plasma between MCI patients and control group. In contrast to the former research, they observed significantly elevated or declined plasma levels of $24 \mathrm{~S}-\mathrm{OHC}$ in $\mathrm{AD}$, vascular disease $(\mathrm{VaD})$ and $\mathrm{MCI}$ participants [29, 30]. These conflicting findings may result from study population with different time after being diagnosed

Table 4 Results of univariate and multivariate regression analysis for 27-OHC

\begin{tabular}{|c|c|c|c|}
\hline \multirow[t]{2}{*}{ Model } & \multicolumn{2}{|c|}{ Odds ratio and $95 \%$ confidence interval } & \multirow[t]{2}{*}{$P$ value } \\
\hline & Low $27-\mathrm{OHC}$ & High 27-OHC & \\
\hline Unadjusted & Ref & $3.21(1.76-5.85)$ & $<0.01$ \\
\hline Adjusted $^{\mathrm{a}}$ & Ref & $2.86(1.52-5.37)$ & $<0.01$ \\
\hline
\end{tabular}

${ }^{\mathrm{a}}$ Adjusted for demographic and risk factors 


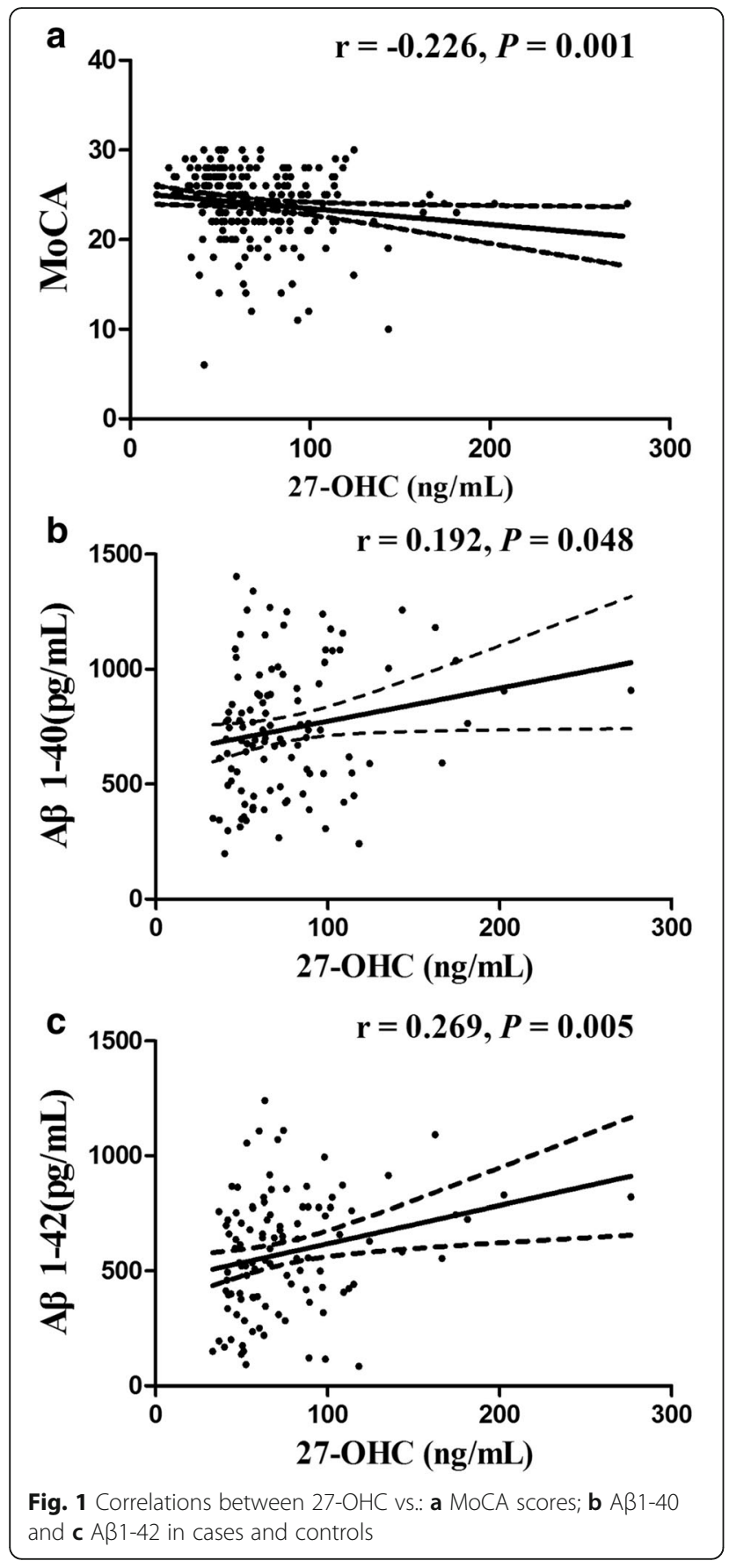

with MCI. The late MCI patients with the loss of neuronal cells had decreased level of $24 \mathrm{~S}-\mathrm{OHC}$ whereas the early MCI patients were characterized by the increase of $24 \mathrm{~S}-\mathrm{OHC}$ probably as a consequence of the released cholesterol caused by the myelin disruption [31].

Unlike $27-\mathrm{OHC}$ and $24 \mathrm{~S}-\mathrm{OHC}, 7 \beta-\mathrm{OHC}$ is generated by non-enzymatic oxidation whereas $7 \alpha-\mathrm{OHC}$ is generated by both non-enzymatic and enzymatic oxidation that is catalyzed by CYP7A1 [32]. The effects of $7 \alpha-\mathrm{OHC}$ and $7 \beta-\mathrm{OHC}$ on cognitive function are less known. MCI falls in between normal forgetfulness and AD. It is accepted that early intervention in MCI including decreasing the risk factors is useful. Our findings has offered some valid epidemiological evidence to reveal the role of $27-\mathrm{OHC}$ in the pathogenesis of $\mathrm{MCI}$, which may provide new insights into the prevention of AD. Some experiments in cell cultures and animals have suggested increased levels of 27$\mathrm{OHC}$ may trigger or accelerate progression of $\mathrm{AD}$ or $\mathrm{MCI}$ through a variety of mechanisms. However, efforts to find out the role of 27-OHC in AD or MCI are still necessary by further human studies. The strengths of our study was a matched case-control study after adjustment for confounders and based on standardized epidemiological methods. Additionally, we enrolled MCI patients without medication as the target population in order to more directly investigate the relationship with risk factors than $\mathrm{AD}$ patients and take preventive measures in the preclinical stage of $\mathrm{AD}$. However, it was a case-control study that can not establish the timeline of exposure to disease outcome, prospective cohort studies are also needed to further evaluate the role of oxysterols in $\mathrm{AD}$ or $\mathrm{MCI}$.

\section{Conclusions}

In conclusion, our findings suggested plasma level of 27-OHC was significantly higher in MCI patients than controls with normal cognition and the increased plasma level of 27-OHC was significantly associated with MCI. Prospective cohort studies and experiments in vitro are needed to further evaluate the potential role of 27-OHC and other oxysterols in involvement in $\mathrm{AD}$ or MCI.

\section{Abbreviations \\ 24S-OHC: 24S-hydroxycholesterol; 27-OHC: 27-hydroxycholesterol; 7a-OHC: 7a-hydroxycholesterol; 7 $\beta-O H C: 7 \beta$-hydroxycholesterol; AD: Alzheimer's disease; HPLC-MS: High Performance Liquid Chromatography-Mass Spectrometry; $\mathrm{MCl}$ : Mild cognitive impairment}

\section{Acknowledgements}

Not applicable.

\section{Funding}

The research was supported by the State Key Program of the National Natural Science Foundation of China (Grant No. 81330065).

\section{Availability of data and materials}

The datasets during and/or analyzed during the current study available from the corresponding author on reasonable request.

\section{Authors' contributions}

$\mathrm{RX}$ : conceived and designed the study; QL, YA and HY: measured the oxysterols, analyzed experimental results and wrote the manuscript; $\mathrm{YL}, \mathrm{CW}$ and LF: assessed cognitive function of all the subjects. All authors read and approved the final manuscript.

Competing interests

The authors declare that they have no competing interests.

\section{Consent for publication}

All the co-authors and participants have gave their consent for publication in Lipids in Health and Disease. 


\section{Ethics approval and consent to participate}

The study design was ethically approved by the Ethics Committee of Capital Medical University (2013SY35). All participants were provided written informed consent at the beginning of the study.

\section{Received: 7 April 2016 Accepted: 28 September 2016} Published online: 10 October 2016

\section{References}

1. Swaminathan A, Jicha GA. Nutrition and prevention of Alzheimer's dementia. Front Aging Neurosci. 2014;6:282.

2. Li X, Song D, Leng SX. Link between type 2 diabetes and Alzheimer's disease: from epidemiology to mechanism and treatment. Clin Interv Aging. 2015;10:549-60.

3. Albert MS, DeKosky ST, Dickson D, Dubois B, Feldman HH, Fox NC, Gamst A, Holtzman DM, Jagust WJ, Petersen RC, et al. The diagnosis of mild cognitive impairment due to Alzheimer's disease: recommendations from the National Institute on Aging-Alzheimer's Association workgroups on diagnostic guidelines for Alzheimer's disease. Alzheimers Dement. 2011;7(3):270-9.

4. Zambon D, Quintana M, Mata P, Alonso R, Benavent J, Cruz-Sanchez F, Gich J, Pocovi M, Civeira F, Capurro S, et al. Higher incidence of mild cognitive impairment in familial hypercholesterolemia. Am J Med. 2010;123(3):267-74.

5. McGuinness B, Craig D, Bullock R, Malouf R, Passmore P. Statins for the treatment of dementia. Cochrane Database Syst Rev. 2014;7:D7514.

6. Bjorkhem I, Meaney S. Brain cholesterol: long secret life behind a barrier. Arterioscler Thromb Vasc Biol. 2004;24(5):806-15.

7. Bjorkhem I, Cedazo-Minguez A, Leoni V, Meaney S. Oxysterols and neurodegenerative diseases. Mol Aspects Med. 2009;30(3):171-9.

8. Daugvilaite V, Arfelt KN, Benned-Jensen T, Sailer AW, Rosenkilde MM Oxysterol-EBI2 signaling in immune regulation and viral infection. Eur J Immunol. 2014;44(7):1904-12.

9. Olkkonen VM, Beaslas O, Nissila E. Oxysterols and their cellular effectors. Biomolecules. 2012;2(1):76-103.

10. Lee WR, Ishikawa T, Umetani M. The interaction between metabolism, cancer and cardiovascular disease, connected by 27-hydroxycholesterol. Clin Lipidol. 2014;9(6):617-24.

11. Bjorkhem I. Crossing the barrier: oxysterols as cholesterol transporters and metabolic modulators in the brain. J Intern Med. 2006;260(6):493-508.

12. Launer $\amalg$, White LR, Petrovitch $H$, Ross GW, Curb JD. Cholesterol and neuropathologic markers of AD: a population-based autopsy study. Neurology. 2001;57(8):1447-52

13. Pappolla MA, Bryant-Thomas TK, Herbert D, Pacheco J, Fabra GM, Manjon M, Girones X, Henry TL, Matsubara E, Zambon D, et al. Mild hypercholesterolemia is an early risk factor for the development of Alzheimer amyloid pathology. Neurology. 2003;61(2):199-205.

14. Kivipelto M, Helkala EL, Laakso MP, Hanninen T, Hallikainen M, Alhainen K, Soininen $\mathrm{H}$, Tuomilehto J, Nissinen A. Midlife vascular risk factors and Alzheimer's disease in later life: longitudinal, population based study. BMJ. 2001;322(7300):1447-51.

15. Mateos L, Ismail MA, Gil-Bea FJ, Leoni V, Winblad B, Bjorkhem I, Cedazo-Minguez A. Upregulation of brain renin angiotensin system by 27-hydroxycholesterol in Alzheimer's disease. J Alzheimers Dis. 2011;24(4):669-79.

16. Heverin M, Maioli S, Pham T, Mateos L, Camporesi E, Ali Z, Winblad B, Cedazo-Minguez A, Bjorkhem I. 27-hydroxycholesterol mediates negative effects of dietary cholesterol on cognition in mice. Behav Brain Res. 2015:278:356-9.

17. Shafaati M, Marutle A, Pettersson H, Lovgren-Sandblom A, Olin M, Pikuleva I, Winblad B, Nordberg A, Bjorkhem I. Marked accumulation of 27-hydroxycholesterol in the brains of Alzheimer's patients with the Swedish APP 670/671 mutation. J Lipid Res. 2011;52(5):1004-10.

18. Jenner AM, Lim WL, Ng MP, Wenk MR, Shui G, Sharman MJ, Gandy SE, Martins RN. The effect of APOE genotype on brain levels of oxysterols in young and old human APOE epsilon2, epsilon3 and epsilon4 knock-in mice. Neuroscience. 2010;169(1):109-15.

19. Folstein MF, Folstein SE, McHugh PR. "Mini-mental state". A practical method for grading the cognitive state of patients for the clinician. J Psychiatr Res. 1975;12(3):189-98.

20. Lu J, Li D, Li F, Zhou A, Wang F, Zuo X, Jia XF, Song H, Jia J. Montreal cognitive assessment in detecting cognitive impairment in Chinese elderly individuals: a population-based study. J Geriatr Psychiatry Neurol. 2011;24(4):184-90.
21. Burkard I, Rentsch KM, von Eckardstein A. Determination of 24S- and 27-hydroxycholesterol in plasma by high-performance liquid chromatography-mass spectrometry. J Lipid Res. 2004;45(4):776-81.

22. van den Kommer TN, Dik MG, Comijs HC, Lutjohann D, Lips P, Jonker C, Deeg DJ. The role of extracerebral cholesterol homeostasis and ApoE e4 in cognitive decline. Neurobiol Aging. 2012;33(3):617-22.

23. Leoni V, Masterman T, Mousavi FS, Wretlind B, Wahlund LO, Diczfalusy U, Hillert J, Bjorkhem I. Diagnostic use of cerebral and extracerebral oxysterols. Clin Chem Lab Med. 2004;42(2):186-91.

24. Llado-Saz S, Atienza M, Cantero JL. Increased levels of plasma amyloid-beta are related to cortical thinning and cognitive decline in cognitively normal elderly subjects. Neurobiol Aging. 2015;36(10):2791-7.

25. Marwarha G, Dasari B, Prasanthi JR, Schommer J, Ghribi O. Leptin reduces the accumulation of Abeta and phosphorylated tau induced by 27-hydroxycholesterol in rabbit organotypic slices. J Alzheimers Dis. 2010;19(3):1007-19.

26. Prasanthi JR, Huls A, Thomasson S, Thompson A, Schommer E, Ghribi O. Differential effects of 24-hydroxycholesterol and 27-hydroxycholesterol on beta-amyloid precursor protein levels and processing in human neuroblastoma SH-SY5Y cells. Mol Neurodegener. 2009;4:1.

27. Hughes TM, Kuller LH, Lopez OL, Becker JT, Evans RW, Sutton-Tyrrell K, Rosano C. Markers of cholesterol metabolism in the brain show stronger associations with cerebrovascular disease than Alzheimer's disease. J Alzheimers Dis. 2012;30(1):53-61.

28. Kolsch H, Heun R, Kerksiek A, Bergmann KV, Maier W, Lutjohann D. Altered levels of plasma 24S- and 27-hydroxycholesterol in demented patients. Neurosci Lett. 2004;368(3):303-8.

29. Papassotiropoulos A, Lutjohann D, Bagli M, Locatelli S, Jessen F, Rao ML, Maier W, Bjorkhem I, von Bergmann K, Heun R. Plasma 24S-hydroxycholesterol: a peripheral indicator of neuronal degeneration and potential state marker for Alzheimer's disease. Neuroreport. 2000;11(9):1959-62.

30. Lutjohann D, Papassotiropoulos A, Bjorkhem I, Locatelli S, Bagli M, Oehring RD, Schlegel U, Jessen F, Rao ML, von Bergmann K, et al. Plasma 24S-hydroxycholesterol (cerebrosterol) is increased in Alzheimer and vascular demented patients. J Lipid Res. 2000;41(2):195-8.

31. Hughes TM, Rosano C, Evans RW, Kuller LH. Brain cholesterol metabolism, oxysterols, and dementia. J Alzheimers Dis. 2013;33(4):891-911.

32. Saito Y, Noguchi N. 7-Hydroxycholestrol as a possible biomarker of cellular lipid peroxidation: difference between cellular and plasma lipid peroxidation. Biochem Biophys Res Commun. 2014;446(3):741-4.

\section{Submit your next manuscript to BioMed Central and we will help you at every step:}

- We accept pre-submission inquiries

- Our selector tool helps you to find the most relevant journal

- We provide round the clock customer support

- Convenient online submission

- Thorough peer review

- Inclusion in PubMed and all major indexing services

- Maximum visibility for your research

Submit your manuscript at www.biomedcentral.com/submit
) Biomed Central 